\title{
Numerical Study of Pollutant Emissions in a Jet Stirred Reactor under Elevated Pressure Lean Premixed Conditions
}

\author{
Karim Mazaheri and Alireza Shakeri \\ Center of Excellence of Aerospace Systems, Sharif University of Technology, Tehran 14588 33351, Iran \\ Correspondence should be addressed to Alireza Shakeri; a_shakeri@ae.sharif.edu
}

Received 5 August 2015; Revised 31 January 2016; Accepted 15 February 2016

Academic Editor: Gerhard-Wilhelm Weber

Copyright (C) 2016 K. Mazaheri and A. Shakeri. This is an open access article distributed under the Creative Commons Attribution License, which permits unrestricted use, distribution, and reproduction in any medium, provided the original work is properly cited.

\begin{abstract}
Numerical study of pollutant emissions (NO and CO) in a Jet Stirred Reactor (JSR) combustor for methane oxidation under Elevated Pressure Lean Premixed (EPLP) conditions is presented. A Detailed Flow-field Simplified Chemistry (DFSC) method, a low computational cost method, is employed for predicting NO and CO concentrations. Reynolds Averaged Navier Stokes (RANS) equations with species transport equations are solved. Improved-coefficient five-step global mechanisms derived from a new evolutionary-based approach were taken as combustion kinetics. For modeling turbulent flow field, Reynolds Stress Model (RSM), and for turbulence chemistry interactions, finite rate-Eddy dissipation model are employed. Effects of pressure (3, 6.5 bars) and inlet temperature $(408-573 \mathrm{~K})$ over a range of residence time (1.49-3.97 ms) are numerically examined. A good agreement between the numerical and experimental distribution of $\mathrm{NO}$ and $\mathrm{CO}$ was found. The effect of decreasing the operating pressure on NO generation is much more than the effect of increase in the inlet temperature.
\end{abstract}

\section{Introduction}

In recent decades, natural-gas-fired turbine industries have been proceeded to lean premixed technology due to stringent environment regulations especially for $\mathrm{NO}_{x}$ suppression, and Elevated Pressure Lean Premixed (hereinafter referred to as EPLP) has been recognized as the practical operating condition. Numerical investigation of pollutant emissions in a combustor under such conditions relies on employing both the suitable method of pollutant prediction and chemical kinetics. However, due to high computational cost for a realscale combustor, the laboratory-scale combustors, that is, Jet Stirred Reactor (JSR), may be emphasized. Issues mentioned above are briefly reviewed in the following paragraphs.

Generally, four different numerical schemes can be found in the literature for predicting of $\mathrm{NO}$ and $\mathrm{CO}$ emissions, Detailed Flow-field Detailed Chemistry (DFDC), Detailed Flow-field Simplified Chemistry (DFSC), Simplified Flowfield Detailed Chemistry (SFDC), and Simplified Flow-field Simplified Chemistry (SFSC). In the first, 2D/3D numerical solution must be performed using a detailed mechanism, and despite very high accuracy of this method, the computational cost is huge; therefore, it is barely used for industrial applications [1]. In the $2 \mathrm{nd}$, a 2D/3D numerical solution using a reduced (or global) mechanism may be applied. This scheme is used for predicting of $\mathrm{NO}$ and $\mathrm{CO}$ emissions for some combustors under lean premixed conditions, that is, Hamer and Roby [2], Nicol et al. [3], and Novosselov and Malte [4]. In the 3rd, a detailed mechanism is employed in a Chemical Reactor Network (CRN) created based on either analyzed numerical results or empirical data, for example, Glarborg et al. [5], Miller and Bowman [6], Drake and Blint [7], Michaud et al. [8], and Nicol et al. [9]. In the last method, instead of a detailed mechanism used in the third method, a simplified mechanism is replaced. This scheme is used by Novosselov and Malte [4].

Mostly, two different chemical kinetic mechanisms, including detailed and simplified, are available for methane oxidation and $\mathrm{NO}$ formation. Limited numbers of detailed mechanisms are available, for instance, GMK [5], MB [6], DB [7], GRI 2.11, GRI 3.0, Hughes et al. [10], Petersen et al. [11], and Pillier et al. [12]. However, there are a large number of studies on simplified mechanisms, for example, Goussis and Kelly, 1990 [13], Lam and Goussis, 1994 [14], Mallampalli et al., 
1998 [15], Massias et al. [1], Sung et al., 2001 [16], Belcadi et al., 2012 [17], and Karalus et al. [18]. Utilizing such mechanisms in computational fluid dynamics (CFD) problems needs a huge computational cost due to high number of species. Furthermore, despite introducing a few numbers of global mechanisms with less number of species, for example, Nicol et al. [3] and Novosselov [19], the rate coefficients of these mechanisms are case dependent and of limited use for variety of operating conditions especially for EPLP situations.

There exist a lot of studies about lean premixed JSR combustors. First time, Thornton et al. [20] experimentally studied this combustor to investigate the kinetic oxidation of the hydrocarbon fuels. Corr et al. [21] investigated the formation of $\mathrm{NO}$ and $\mathrm{CO}$ in JSR with the volume of $15.8 \mathrm{cc}$ under atmospheric pressure lean premixed conditions $(\phi=$ 0.6) using experiment and a PSR solver. Steele et al. [22] did a similar work but over a range of equivalence ratio (0.41-0.67) and residence time (1.7-7.4 ms). Furthermore, Steele et al. [23] examined effects of inlet temperature (300-600 K), pressure (1-7.1 atm), volume $(2,16 \mathrm{cc})$, and the ratio of area to volume using a solver consisting of a PSR and a plug flow reactor (PFR). Bengtsson et al. [24] used alternative conditions in the experiment, that is, pressure up to 20 bars, equivalence ratio of 0.55 , a range of temperature (1783-1823 K), and three different residence times (1.0, 1.5, and $2.0 \mathrm{~ms})$. Shuman [25] empirically inspected the formation of $\mathrm{NO}$ and $\mathrm{CO}$ over a wider range for residence time $(0.5-4.0 \mathrm{~ms})$, temperature (1815$1910 \mathrm{~K})$, and different range for pressure (3-6.5 atm.) and inlet temperature (344-573 K).

The main objective of this study is to numerically investigate effects of pressure and inlet temperature and a range of residence time on $\mathrm{NO}$ and $\mathrm{CO}$ emissions in a laboratory-scale JSR combustor under EPLP operating conditions. Nine operating conditions from the experiment of Shuman [25] and general form of the five-step global mechanism suggested by Nicol et al. [3] are considered as the base operating conditions and base mechanism, respectively. However, in this mechanism the rate coefficients include analytical relationships between the reaction rate and the net rate of species. They have used regression analysis based on the mechanism of $\mathrm{MB}$, but he did not present his model for high pressure condition. In addition, the effect of some parameters such as initial temperature of the mixture on rate coefficients was not considered. Here, the optimization is improved by using the $\mathrm{DE}$ algorithm. In this way we do not need any analytical relationship, and the optimal rate coefficients corresponding to the desired operating conditions are determined. So, the new evolutionary-based approach is used to obtain the reaction rate coefficients of this mechanism under nine EPLP operating conditions. A DFSC scheme using CFD software (FLUENT) is employed to numerical simulation.

\section{Derivation of Chemical Kinetic Coefficients}

A new evolutionary-based approach is implemented to obtain the reaction rate coefficients of the methane-air combustion kinetics, and the details are elaborately explained in the following subsections. The method consists of two modules, namely, the simple Chemical Reactor Modeling (CRM) and the numerical optimizer. For any given operating condition and a user defined detailed mechanism (as the target mechanism), the CRM gives the corresponding values of species concentrations, that is, $\mathrm{NO}$ and $\mathrm{CO}$. These are reserved as the target values for optimizer module. With the aim of predicting NO and CO, a global mechanism is specified. The unknown rate coefficients of this global mechanism are considered as the design variables used in the differential evolution (DE) module. Employing an interactive process, the CRM calculates the species concentrations through the coefficients which are obtained by the DE. The results are compared with the detailed mechanism and this process is continued till the discrepancy between the predicted and the target values becomes as small as possible.

2.1. The Chemical Reactor Modeling (CRM). According to the previous paragraph, species concentrations are obtained from the CRM module. Here, a Perfectly Stirred Reactor (PSR) combined with a plug flow reactor (PFR) is addressed as the CRM. Possible detailed or predefined global mechanisms along with a set of parameters, that is, operating pressure, initial mixture temperature, residence time, and equivalence ratio, are the inputs. Furthermore, the length and diameter of the combustor are also added. The CRM calculations have been carried out using the method described by Turns [26]. It is noted that CHEMKIN [27] software is used for the calculation of CRM. The PSR-PFR output is distribution of concentrations along the reactor.

2.2. Optimizer Module. In this study, the differential evolution (DE) optimization algorithm [28] is employed to find the rate coefficients for a predefined global mechanism through the procedure addressed in Section 2. Three key elements should be provided for the optimizer module, (i) the design variables, (ii) the objective function, and (iii) the constraints. The design variables are the unknown rate coefficients of the global mechanism. The cost function is intended to evaluate the deviation of some species concentrations (i.e., NO and CO) predicted using the global mechanism from those calculated with the detailed mechanism. Consequently, the cost function for the PSR-PFR is specified as

$$
\begin{aligned}
I_{\mathrm{PFR}}= & \frac{1}{X_{\mathrm{NO}}^{\mathrm{det}, \mathrm{max}}} \int_{0}^{L}\left|X_{\mathrm{NO}}^{\mathrm{det}}(x)-X_{\mathrm{NO}}^{\mathrm{glb}}(x)\right| d x \\
& +\frac{1}{X_{\mathrm{CO}}^{\mathrm{det}, \mathrm{max}}} \int_{0}^{L}\left|X_{\mathrm{CO}}^{\mathrm{det}}(x)-X_{\mathrm{CO}}^{\mathrm{glb}}(x)\right| d x,
\end{aligned}
$$

where $x, X, L$ are distance along the PFR, mole fraction, and length of the reactor, respectively. Also, det and glb denote detailed and global mechanism, respectively. The optimization constraints are imposed by considering a finite interval for each design variable. The intervals are assigned such that the best values lie between the lower and the upper bounds. The objective function is normalized based on the maximum mole fraction of $\mathrm{NO}$ and $\mathrm{CO}$. It is obvious that one may add other target mole fractions to the above, but then the model accuracy for predicting these two species will decrease. 
TABLE 1: Base operating conditions [25].

\begin{tabular}{|c|c|c|c|c|c|c|}
\hline Case number & $\tau(\mathrm{ms})$ & $\phi(-)$ & $T_{t 0}(\mathrm{~K})$ & $P($ atm $)$ & Fuel flow (gr/sec) & $\mathrm{PH} / \mathrm{NPH}^{*}$ \\
\hline 1 & 1.49 & 0.58 & 573 & 6.5 & 1.219 & PH \\
\hline 2 & 2.09 & 0.61 & 573 & 6.5 & 0.871 & $\mathrm{PH}$ \\
\hline 3 & 3.97 & 0.66 & 573 & 6.5 & 0.460 & $\mathrm{PH}$ \\
\hline 4 & 1.65 & 0.64 & 573 & 3 & 0.523 & $\mathrm{PH}$ \\
\hline 5 & 2.36 & 0.67 & 573 & 3 & 0.366 & $\mathrm{PH}$ \\
\hline 6 & 3.33 & 0.74 & 573 & 3 & 0.259 & $\mathrm{PH}$ \\
\hline 7 & 1.63 & 0.69 & 408 & 3 & 0.526 & $\mathrm{NPH}$ \\
\hline 8 & 2.40 & 0.74 & 418 & 3 & 0.360 & $\mathrm{NPH}$ \\
\hline 9 & 3.33 & 0.80 & 432 & 3 & 0.260 & $\mathrm{NPH}$ \\
\hline
\end{tabular}

${ }^{*} \mathrm{PH}$ : preheated conditions, NPH: no preheated conditions.

TABLE 2: General form of the five-step global mechanisms for $\mathrm{CH}_{4}$ air combustion [3].

\begin{tabular}{|c|c|c|}
\hline Number & Reaction description & Reaction rate $\left[\mathrm{mole} / \mathrm{cm}^{3} / \mathrm{s}\right]$ \\
\hline 1 & $\mathrm{CH}_{4}+1.5 \mathrm{O}_{2} \rightarrow \mathrm{CO}+2 \mathrm{H}_{2} \mathrm{O}$ & $R_{1}=A_{1}\left[\mathrm{CH}_{4}\right]^{B_{1}}\left[\mathrm{O}_{2}\right]^{C_{1}} \exp \left(-D_{1} / R_{u} / T\right)$ \\
\hline 2 & $\mathrm{CO}+0.5 \mathrm{O}_{2} \rightarrow \mathrm{CO}_{2}$ & $R_{2}=A_{2}[\mathrm{CO}]_{2}^{B}\left[\mathrm{O}_{2}\right]_{2}^{C} \exp \left(-D_{2} / R_{u} / T\right)$ \\
\hline 3 & $\mathrm{CO}_{2} \rightarrow \mathrm{CO}+0.5 \mathrm{O}_{2}$ & $R_{3}=A_{3}\left[\mathrm{CO}_{2}\right]_{3}^{B} \exp \left(-D_{3} / R_{u} / T\right)$ \\
\hline 4 & $\mathrm{~N}_{2}+\mathrm{O}_{2}+\mathrm{CO} \rightarrow 2 \mathrm{NO}+\mathrm{CO}$ & $R_{4}=A_{4}\left[\mathrm{O}_{2}\right]_{4}^{B}[\mathrm{CO}]_{4}^{C} \exp \left(-D_{4} / R_{u} / T\right)$ \\
\hline 5 & $\mathrm{~N}_{2}+\mathrm{O}_{2} \rightarrow 2 \mathrm{NO}$ & $R_{5}=A_{5} T^{-0.5}\left[\mathrm{~N}_{2}\right]\left[\mathrm{O}_{2}\right] \exp \left(-D_{5} / R_{u} / T\right)$ \\
\hline
\end{tabular}

2.3. Base Operating Conditions and Global Mechanism. The above procedure has been applied to generate nine models, based on nine operating conditions. These operating conditions are selected based on the studies of Shuman [25]. In all cases, the combustion pressure is estimated from pressure loss in the premixed tube, nozzle inlet, and combustor Mach number. Similar estimates are used to deduce the residence time based on the flow parameters and combustor volume. All the flow parameters are given in Table 1 and the combustor volume is assumed equal to $1.0 \mathrm{~cm}^{3}$.

The general form of the five-step global mechanism proposed by Nicol et al. [3] is considered as the base mechanism. This mechanism and its unknown rate parameters are presented in Table 2. According to Table 2, the five steps of the mechanism are as follows: oxidation of the methane fuel to $\mathrm{CO}$ and $\mathrm{H}_{2} \mathrm{O}$, oxidation of the $\mathrm{CO}$ to $\mathrm{CO}_{2}$, dissociation of the $\mathrm{CO}_{2}$ to $\mathrm{CO}$, flame-NO formation, and post-flame-NO formation.

\section{Numerical Solution Procedure}

JSR combustor together with the relevant geometrical parameters is schematically shown in Figure 1.

This standard geometry is consisted of two truncated cones, one at the first and the other at the end of the combustor, and a cylinder in the middle. Combustor inlet (with diameter of $d_{i}$ ) is located at the center of the lower base, while four equally spaced holes (with individual diameter of $d_{0}$ ), with elevation of $h_{0}$ from the base, are positioned on the lateral surface of the first truncated cone. Several researchers used a similar shape (but with different dimensions) for JSR in their experiments, for example, Corr et al. [21], Steele et al. [22], Steele et al. [23], Steele et al. [29], Shuman [25], and

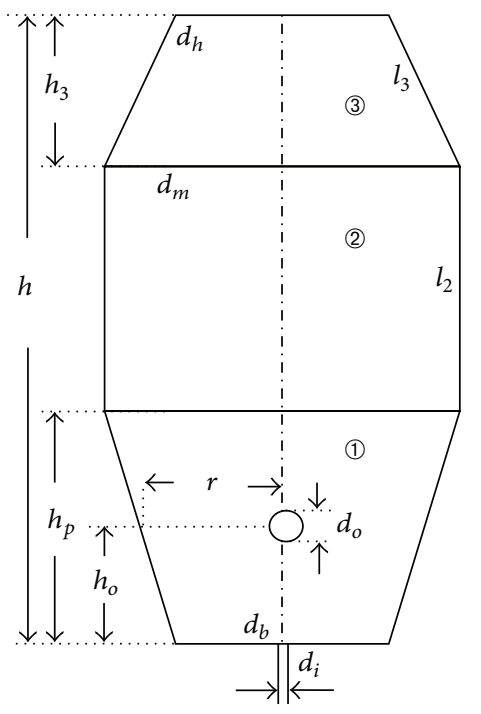

FIGURE 1: JSR combustor geometry.

Rutar and Malte [30]. Some geometrical dimensions of these can be seen in Table 3.

Here, geometry of the JSR of Shuman's work is considered in our numerical study. Since some of the reactors dimensions were not clear in their references, we have used ratio of a power of one-third of their volume to guess unknown dimensions.

3.1. Governing Equations. Here, a brief description of conservation equations for mass, momentum, chemical species, energy, and turbulence is introduced. These equations are 
TABLE 3: Dimensions of different JSRs.

\begin{tabular}{cccccccc}
\hline$d_{i}$ & $d_{o}$ & $d_{b}$ & $d_{m}$ & $h_{1}$ & $h_{o}$ & $h$ & $\forall$ \\
\hline 4.40 & 4.00 & 16.0 & 25.0 & 25.00 & 6.00 & 45.00 & 15.8 \\
4.40 & 4.00 & 16.0 & 25.0 & 25.00 & 6.00 & 45.00 & 15.8 \\
0.74 & 9.50 & - & - & - & - & - & 49.5 \\
4.40 & 4.00 & 16.0 & 25.0 & 25.00 & 6.00 & 45.00 & 15.8 \\
1.00 & 2.40 & - & 12.7 & 14.20 & 14.2 & 22.20 & 2.00 \\
1.40 & 1.27 & 7.30 & 11.5 & 13.46 & - & 20.19 & 1.50 \\
\hline
\end{tabular}

applicable for turbulent flow in a nonaccelerating reference frame, and details are available in certain reference [31].

(i) Conservation of Mass. Continuity equation can be introduced as follows:

$$
\frac{\partial \rho}{\partial t}+\nabla \cdot(\rho \vec{v})=0
$$

where $\rho$ is the density and $\vec{v}$ is the velocity vector.

(ii) Conservation of Momentum. Conservation of momentum is described by

$$
\frac{\partial}{\partial t}(\rho \vec{v})+\nabla \cdot(\rho \vec{v} \vec{v})=-\nabla p+\nabla \cdot(\overline{\bar{\tau}})+\rho \vec{g}+\vec{F},
$$

where $p$ is static pressure, $\overline{\bar{\tau}}$ is the stress tensor, and $\rho \vec{g}$ and $\vec{F}$ are the gravitational body force and external body force, respectively. The stress tensor is described by

$$
\overline{\bar{\tau}}=\mu\left[\left(\nabla \vec{v}+\nabla \vec{v}^{T}\right)-\frac{2}{3} \nabla \cdot \vec{v} I\right],
$$

where $\mu$ is the molecular viscosity and $I$ is the unit tensor.

(iii) Species Transport Equations. The conservation equations for chemical species can be written as

$$
\frac{\partial}{\partial t}\left(\rho Y_{i}\right)+\nabla \cdot\left(\rho \vec{v} Y_{i}\right)=-\nabla \cdot \vec{J}_{i}+R_{i},
$$

where $Y_{i}$ is the mass fraction of each species, $R_{i}$ is the net rate of production of species $i$ by chemical reaction, and $\vec{J}_{i}$ is the diffusion flux of species $i$ and can be written as

$$
\overrightarrow{J_{i}}=-\rho\left(D_{i, m}+\frac{\mu_{t}}{\mathrm{Sc}_{t}}\right) \nabla Y_{i},
$$

where $\mathrm{Sc}_{t}$ is the turbulent Schmidt number, $\mu_{t}$ is turbulent viscosity, and $D_{t}$ is the turbulent diffusivity.

Here, the source terms $R_{i}$ in (5) are computed by Eddy dissipation model.

(v) Turbulence Model. The exact transport equations for the transport of the Reynolds stresses $\left(\rho \overline{\hat{u}_{i} \dot{u}_{j}}\right)$ are also solved as the flow is turbulent. These equations can be written as

$$
\begin{aligned}
& \frac{\partial}{\partial t}\left(\rho \overline{\hat{u}_{i} \dot{u}_{j}}\right)+\frac{\partial}{\partial x_{k}}\left(\rho u_{k} \overline{\dot{u}_{i} \dot{u}_{j}}\right) \\
& \quad=D_{T, i j}+D_{L, i j}+P_{i j}+\emptyset_{i j}+\epsilon_{i j},
\end{aligned}
$$

where $D_{T, i j}$ is turbulent diffusion, $D_{L, i j}$ is molecular diffusion, $P_{i j}$ is stress production, $\emptyset_{i j}$ is pressure strain, and $\epsilon_{i j}$ is dissipation. For details of modeling these terms, it can be referred to Lien and Leschziner [32].

3.2. Grid and Boundary Conditions. We use axisymmetric assumption to reduce the computational cost. The output holes are replaced with a slot with an area equivalent to the area of all four holes. A structured grid consisting of 40000 cells is used for numerical solution. Mass-flow-inlet and pressure-outlet are considered for the inlet and outlet boundaries, respectively. Mass fractions of the both reactants and products are calculated in terms of equivalence ratio considering one-step global mechanism for methane-air combustion. Hydraulic diameter-turbulence intensity approach is used to calculate both kinetics and dissipation rate of turbulence energy. Inlet and outlet diameters are considered as hydraulic diameter, and turbulence intensities are determined based on $I=0.16 \mathrm{Re}_{D}^{-0.125}$.

3.3. Method of Numerical Solution. The CFD software (FLUENT) is used for numerical simulation. For faster convergence, first a cold flow procedure is used and then the reactive-flow simulation is performed. A pressure-based method is employed to solve the RANS equations together with species transport equations. For modeling turbulent flow field, Reynolds Stress Model (RSM), and for turbulence chemistry interactions, finite rate-Eddy dissipation model are used. To discretize the pressure, the standard discretization method of the software is used. For other parameters (i.e., density, momentum, turbulence kinetic energy, dissipation rates, and species concentrations) the upwind scheme is used for discretization. For better convergence, based on our experience an under relaxation factor of 0.6 is used for the turbulence kinetic energy, dissipation rate of energy, and viscosity, and a factor of 0.8 is used for density, energy, and chemical species equations. It is noted that here heat transfer is not modeled.

\section{Validation and Results}

Results are separately presented in three subsections. In Section 4.1, validated results of the generated chemical kinetics using the PSR-PFR module and evolutionary-based method simultaneously are examined over different operating pressures, residence times, and inlet temperatures. In Section 4.2 , the attention is confined to compare the numerical predicted of $\mathrm{NO}$ and $\mathrm{CO}$ emissions with the experiments. Also, grid independency of the numerical solution is performed and results are presented for pollutant species (e.g., $\mathrm{NO}$ and $\mathrm{CO}$ ). In Section 4.3, we turn to investigate effects of operating pressure and inlet temperature on $\mathrm{NO}$ and $\mathrm{CO}$ emissions at different residence times.

4.1. Validated Results of the Obtained Kinetics. Our algorithm is a very fast algorithm which produces a kinetic model for each reactor, at each operating condition (i.e., inlet temperature, pressure, and the total equivalence ratio). As presented 
in Table 1, nine different operating conditions (case numbers) are chosen, six to investigate effects of the combustor pressure and three to examine impacts of the inlet temperature on $\mathrm{NO}$ and $\mathrm{CO}$ concentrations. Mass flow is not a dependent parameter in our analysis but is used in our CFD simulations as part of our boundary conditions. Also as reported in Table 2, the global five-step mechanism of Nicol with unknown reaction rate coefficients is used as the base of our mechanism, and then the optimal values of these unknowns are obtained from the evolutionary-based procedure (explained in Sections 2.1 and 2.2). The calculated coefficients are tabulated for eight case numbers (Table 1 ) in Table 4 . Comparison of the rate coefficients obtained for the temperature and pressure conditions (Table 1) shows that these factors are more a function of pressure and temperature changes have less effect on them.

To compare the computational cost of this 5-step model with a full GRI-3.0 mechanism, we use the PREMIXED model of CHEMKIN software. The computational cost for full mechanism was about 16 times the reduced 5-step mechanism. Since this is a one dimensional model, we expect significant computational cost advantage for real three dimensional computations.

$\mathrm{NO}$ and $\mathrm{CO}$ concentrations and adiabatic flame temperature for nine cases are comparatively plotted in Figures 24 which show that there is a reasonable agreement between the generated five-step mechanisms and the detailed GRI 3.0 mechanism.

4.2. Comparing the Predicted Emissions with Experiment. Some empirical data of Shuman is used for validation of the numerical study. However, the experiments were performed for three different pressures of premixed tube $(3,4.7$, and $6.5 \mathrm{~atm}$. ), residence time, and inlet temperature ranged between $0.5-4.08 \mathrm{~ms}$ and $323-573 \mathrm{~K}$, respectively, at lean equivalence ratios (0.58-0.80); here validations are presented for two different pressures ( 3 and 6.5 atm.) and inlet temperatures $(418$ and $573 \mathrm{~K})$ and three different residence times (2.1, 2.5 , and $4 \mathrm{~ms})$.

Comparison between predicted and empirical data for $\mathrm{NO}$ and CO versus radial coordinate inside the JSR combustor at fixed axial position of $13.46 \mathrm{~mm}$ are illustrated in Figures 5 and 6 for cases 2 and 8 (two different pressures and inlet temperatures).

As is obvious from these figures, there is a reasonable agreement between the numerical and experimental data for different case numbers.

To investigate grid independency of the numerical solution, concentrations of NO and CO for the other case (e.g., case 3 ) based on two meshes with different cells (40000 and 110000) are illustrated in Figure 7 and the distributions are compared with the experiment.

4.3. Effects of Inlet Temperature and Operating Pressure on NO. It is found that increasing residence time under a specified inlet temperature and operating pressure leads to increasing the NO concentration at the exhaust of the JSR combustor. Furthermore, increasing both the inlet temperature and operating pressure at a specified residence time leads to decreasing
TABLE 4: Calculated coefficients of five-step global mechanisms for eight case numbers given in Table 1 .

\begin{tabular}{|c|c|c|c|c|c|}
\hline \multirow{2}{*}{$I$} & \multirow{2}{*}{ Case number } & \multicolumn{4}{|c|}{ Derived coefficients } \\
\hline & & $A$ & $B$ & C & $D$ \\
\hline 1 & & $1.228 e+18$ & 1.40034 & 0.402908 & 57735.3 \\
\hline 2 & & $4.924 e+21$ & 1.41719 & 1.727700 & 39913.7 \\
\hline 3 & 1 & $2.775 e+14$ & 1.00304 & - & 120189 \\
\hline 4 & & $1.281 e+35$ & 4.00016 & 0.849971 & 114989 \\
\hline 5 & & $2.568 e+16$ & - & - & 145000 \\
\hline 1 & & $9.155 e+17$ & 1.5887 & 0.409601 & 44373.2 \\
\hline 2 & & $4.901 e+21$ & 1.51202 & 1.721500 & 35039.7 \\
\hline 3 & 2 & $2.201 e+14$ & 1.00000 & - & 120002 \\
\hline 4 & & $1.318 e+35$ & 4.08662 & 0.836052 & 114839 \\
\hline 5 & & $3.719 e+16$ & - & - & 144979 \\
\hline 1 & & $1.166 e+18$ & 1.59108 & 0.468756 & 42085.8 \\
\hline 2 & & $4.570 e+21$ & 1.51016 & 1.745650 & 34044.6 \\
\hline 3 & 3 & $2.304 e+14$ & 1.00277 & - & 120085 \\
\hline 4 & & $1.059 e+35$ & 4.09869 & 0.846993 & 114377 \\
\hline 5 & & $3.970 e+16$ & - & - & 140660 \\
\hline 1 & & $1.255 e+18$ & 1.40001 & 0.400577 & 40105.8 \\
\hline 2 & & $3.759 e+21$ & 1.53675 & 1.610820 & 34464.8 \\
\hline 3 & 4 & $1.995 e+14$ & 1.00554 & - & 121056 \\
\hline 4 & & $1.043 e+35$ & 4.01789 & 0.849956 & 104282 \\
\hline 5 & & $2.542 e+16$ & - & - & 144977 \\
\hline 1 & & $1.256 e+18$ & 1.45728 & 0.480269 & 40000.2 \\
\hline 2 & & $3.432 e+21$ & 1.53525 & 1.643350 & 33422.8 \\
\hline 3 & 5 & $2.124 e+14$ & 1.00633 & - & 121677 \\
\hline 4 & & $1.068 e+35$ & 4.03624 & 0.849769 & 104989 \\
\hline 5 & & $2.588 e+16$ & - & - & 144994 \\
\hline 1 & & $9.511 e+17$ & 1.40852 & 0.400297 & 40034.4 \\
\hline 2 & & $3.846 e+21$ & 1.51501 & 1.609680 & 38742.8 \\
\hline 3 & 6 & $2.489 e+14$ & 1.00011 & - & 124250 \\
\hline 4 & & $1.235 e+35$ & 4.01041 & 0.849784 & 106649 \\
\hline 5 & & $2.513 e+16$ & - & - & 144999 \\
\hline 1 & & $9.219 e+17$ & 1.41493 & 0.592969 & 40008.7 \\
\hline 2 & & $4.867 e+21$ & 1.51367 & 1.725150 & 30257.7 \\
\hline 3 & 7 & $2.031 e+14$ & 1.00414 & - & 120267 \\
\hline 4 & & $1.315 e+35$ & 4.00065 & 0.843531 & 104076 \\
\hline 5 & & $2.512 e+16$ & - & - & 144693 \\
\hline 1 & & $1.198 e+18$ & 1.51732 & 0.413664 & 40355.4 \\
\hline 2 & & $4.946 e+21$ & 1.53938 & 1.620760 & 35262.2 \\
\hline 3 & 8 & $2.818 e+14$ & 1.00000 & - & 123114 \\
\hline 4 & & $1.190 e+35$ & 4.00200 & 0.849999 & 104004 \\
\hline 5 & & $2.555 e+16$ & - & - & 144994 \\
\hline
\end{tabular}

levels of the exhausted NO. It is quantitatively found that increasing the operating pressure about $116 \%$ may decrease the NO level about $66 \%$, while for inlet temperature the values of $36 \%$ and $3 \%$ are obtained, respectively. Therefore, the impact of operating pressure on NO is about seven times more than the effects of inlet temperature. Concentrations of NO versus residence times at different pressures are illustrated in Figure 8. 


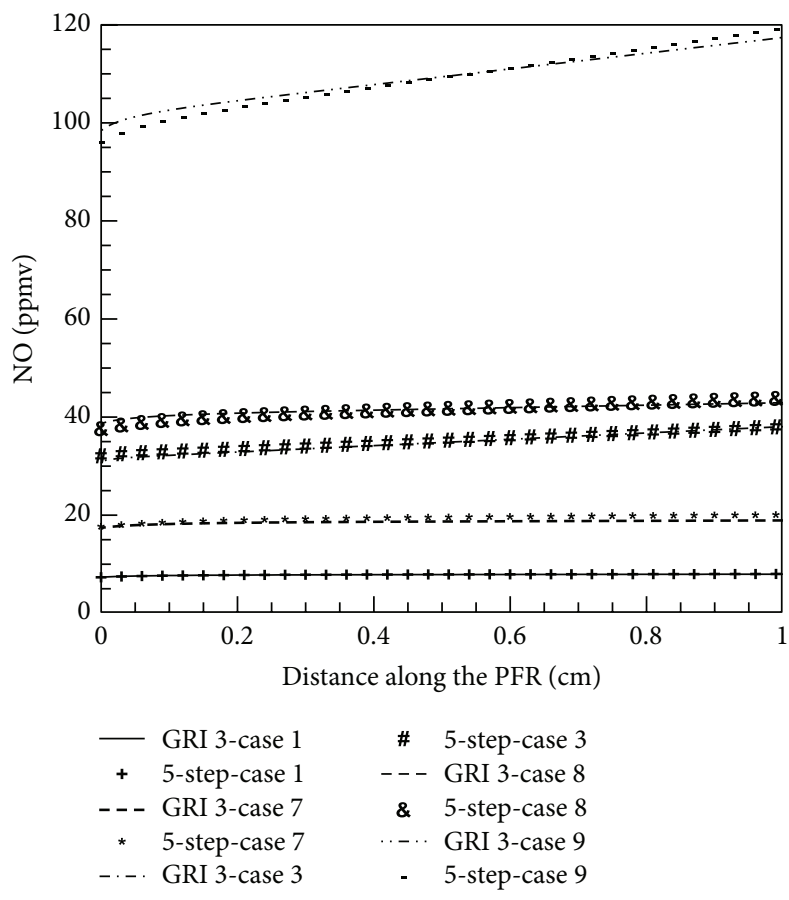

(a)

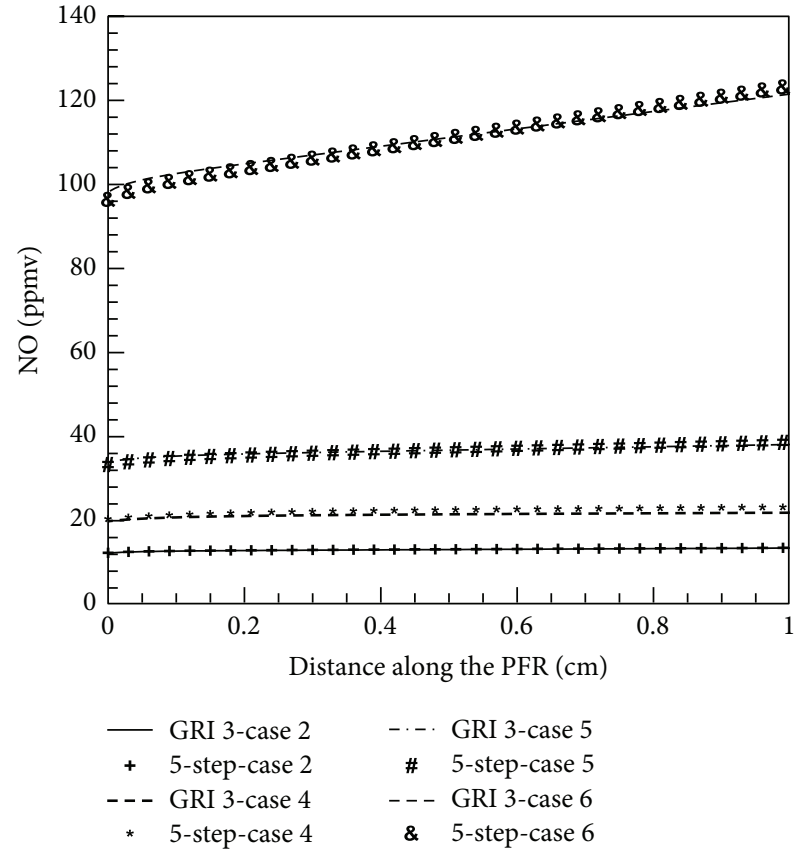

(b)

FIGURE 2: NO concentration versus distance along the PFR using the PSR-PFR based on the generated five-step mechanism for methane oxidation, comparing with GRI 3.0 for different cases of 1, 3, 7, 8, and 9 (a) and 2, 4, 5, and 6 (b).

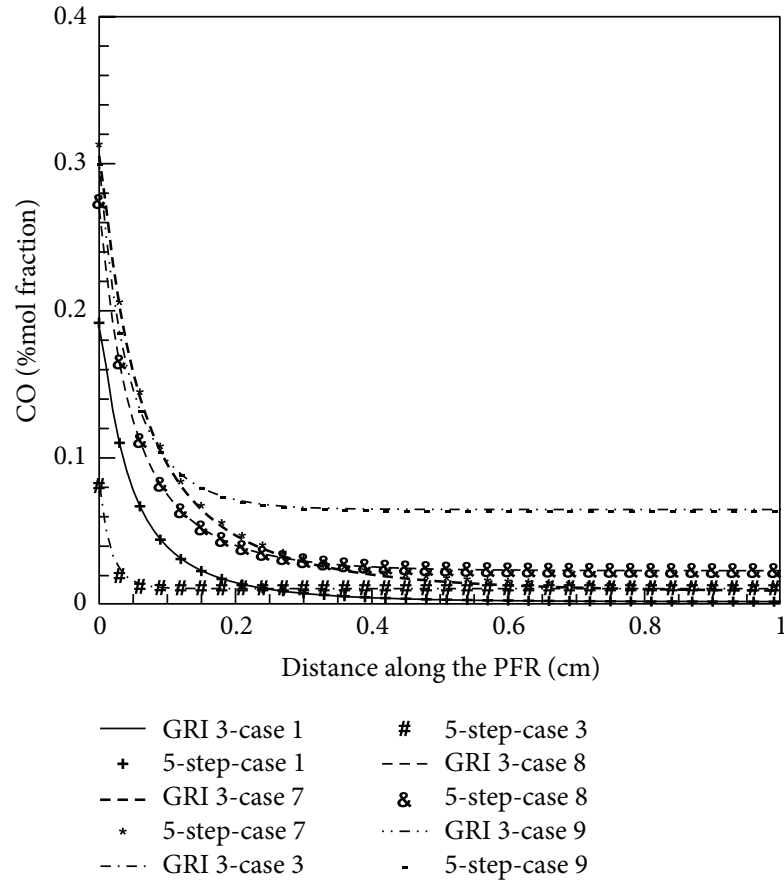

(a)

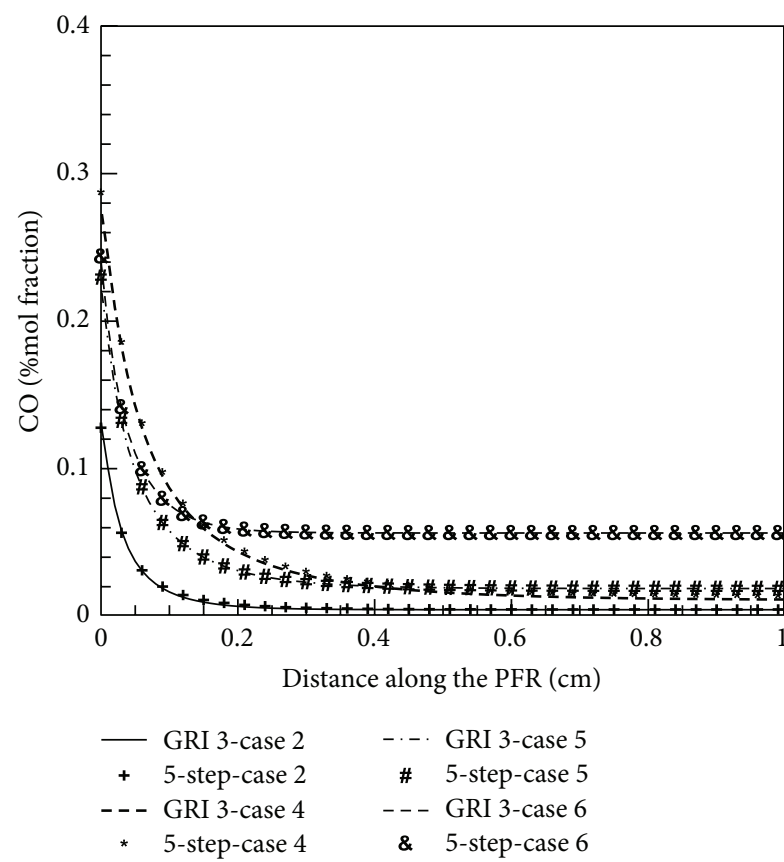

(b)

FIGURE 3: CO concentration versus distance along the PFR using the PSR-PFR based on the generated five-step mechanism for methane oxidation, comparing with GRI 3.0 for different cases of 1, 3, 7, 8, and 9 (a) and 2, 4, 5, and 6 (b). 


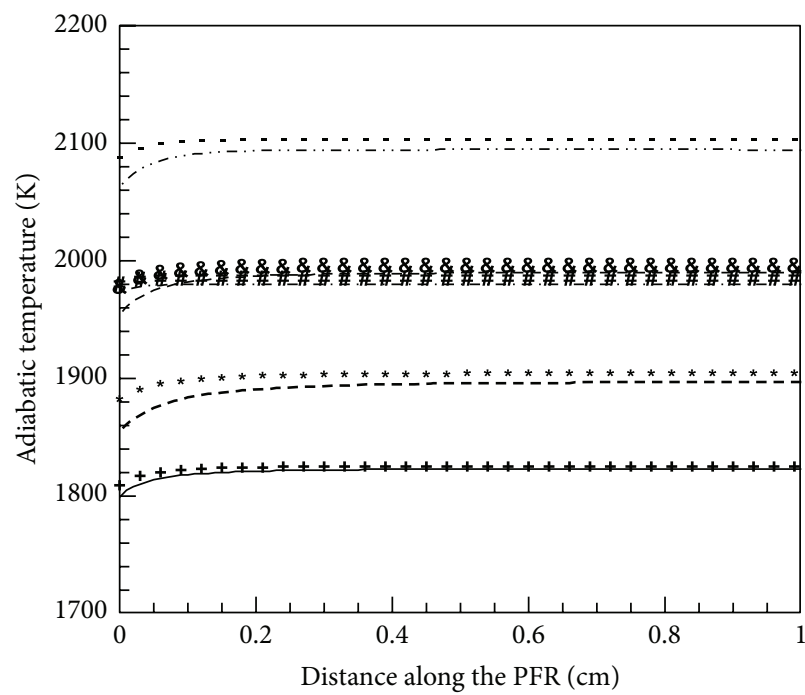

(a)

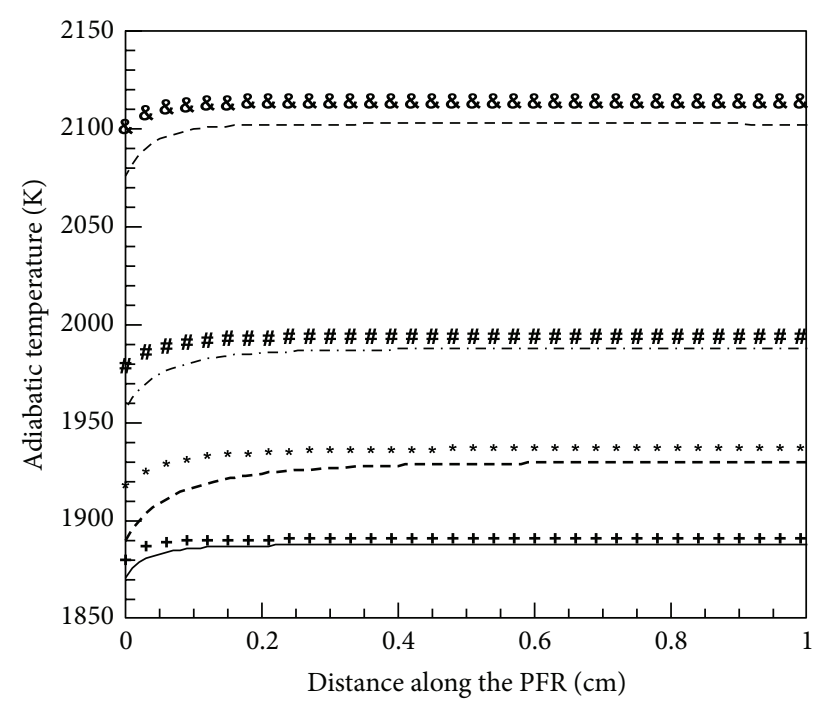

(b)

FIGURE 4: Adiabatic flame temperature versus distance along the PFR using the PSR-PFR based on the generated five-step mechanism for methane oxidation, comparing with GRI 3.0 for different cases of 1, 3, 7, 8, and 9 (a) and 2, 4, 5, and 6 (b).

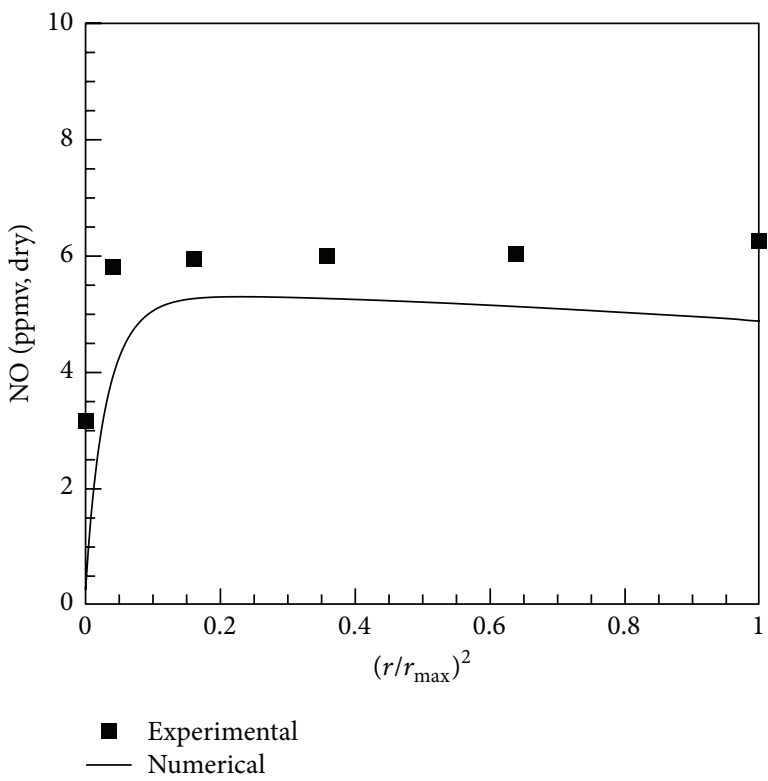

(a)

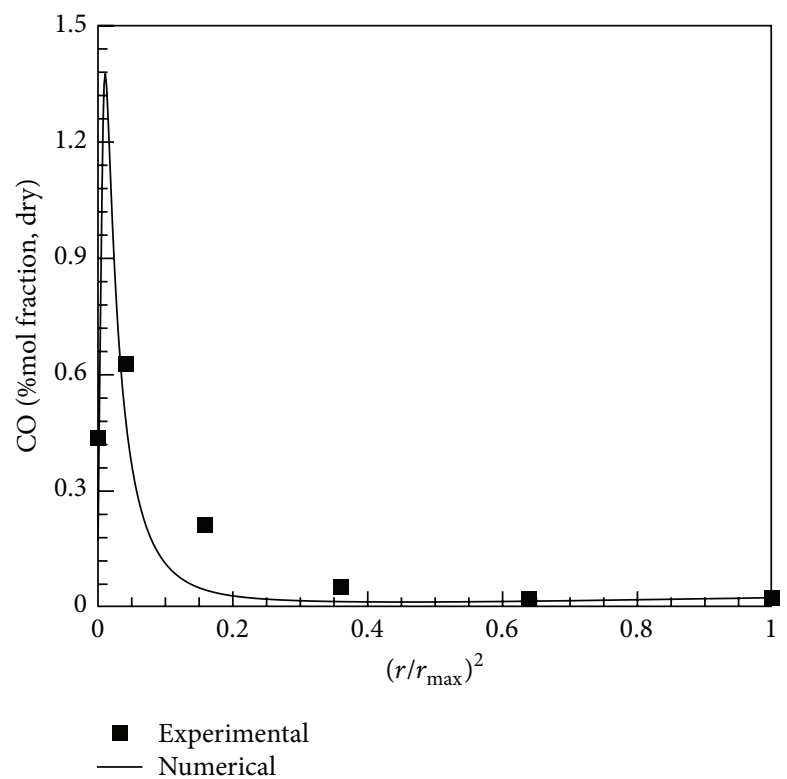

(b)

FIgURE 5: NO (a) and CO (b) concentrations along the radial position between central line and sidewall of the JSR at fixed axial position $(13.46 \mathrm{~mm})$, using the generated five-step mechanism in PSR-PFR obtained from CFD simulation for methane oxidation, comparing with the experimental data for case 2 .

\section{Conclusion}

In this paper, numerical study of pollutant emissions (NO and $\mathrm{CO}$ ) in a Jet Stirred Reactor (JSR) combustor for methane oxidation under Elevated Pressure Lean Premixed (EPLP) conditions has been carried out. A Detailed Flow-field Simplified Chemistry (DFSC) method, a low computational cost approach, has been employed for predicting $\mathrm{NO}$ and $\mathrm{CO}$ concentrations. Effects of pressure (3, 6.5 bars) and inlet temperature (408-573 K) over a range of residence time (1.49-3.97 ms) has been numerically examined. A good agreement between the numerical and experimental distributions for $\mathrm{NO}$ and $\mathrm{CO}$ was found. It was found that increasing both the operating pressure and inlet temperature tends to decrease the NO levels. It was quantitatively found that increasing the operating pressure about $116 \%$ may decrease the NO level about $66 \%$, while for inlet temperature the values of $36 \%$ and $3 \%$ were obtained, respectively. 


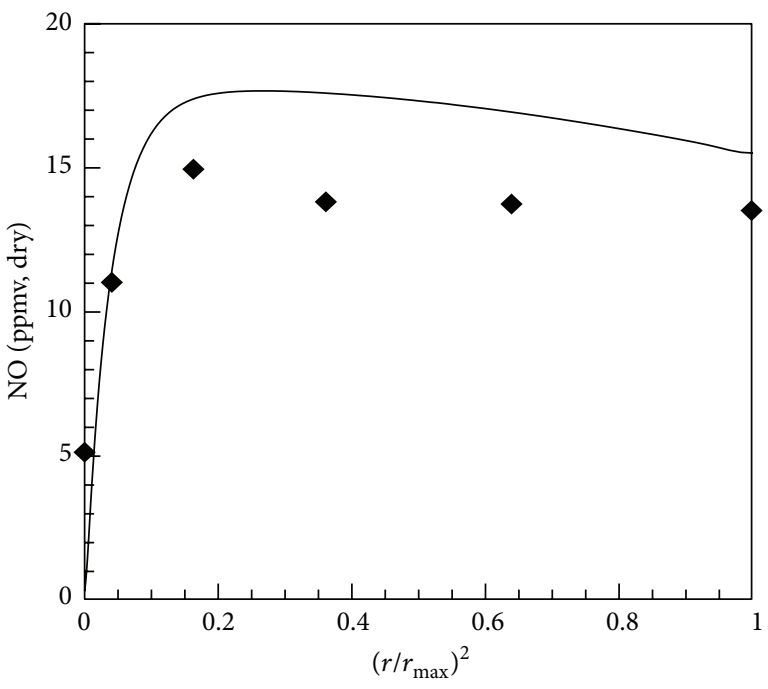

- Experimental Numerical

(a)

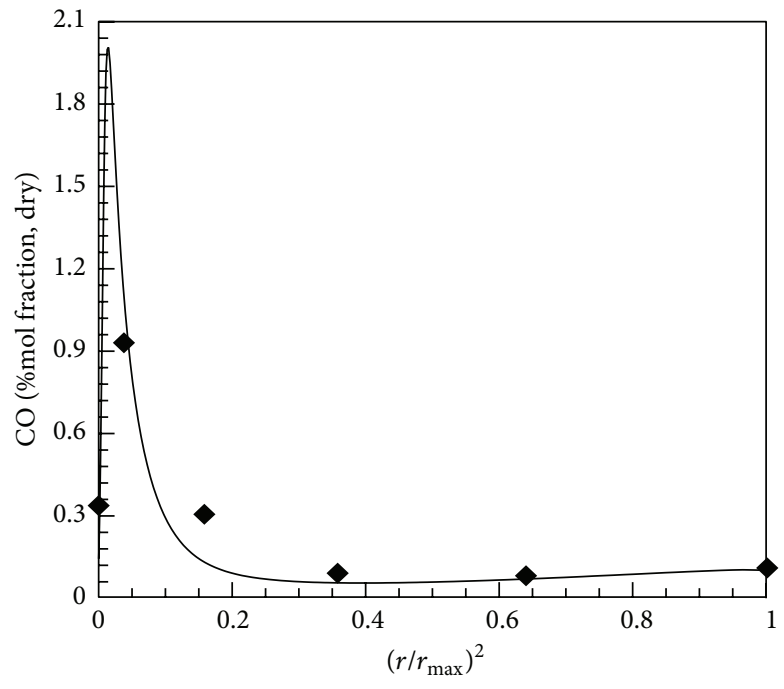

- Experimental

Numerical

FIGURE 6: NO (a) and CO (b) concentrations along the radial position between central line and sidewall of the JSR at fixed axial position $(13.46 \mathrm{~mm})$, using the generated five-step mechanism in PSR-PFR obtained from CFD simulation for methane oxidation, comparing with the experimental data for case 8 .

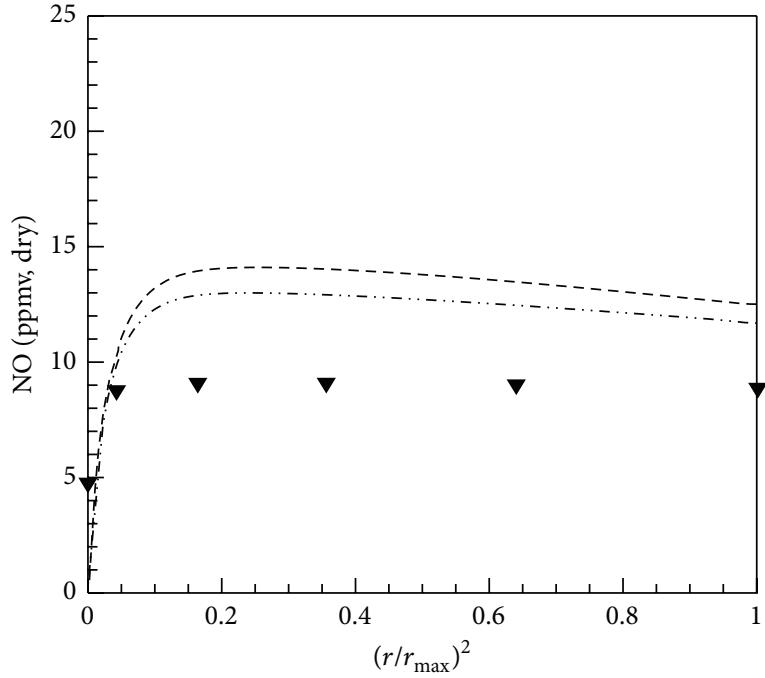

$\boldsymbol{\nabla}$ Experimental

.... Num-110000 cells

- - Num- 40000 cells

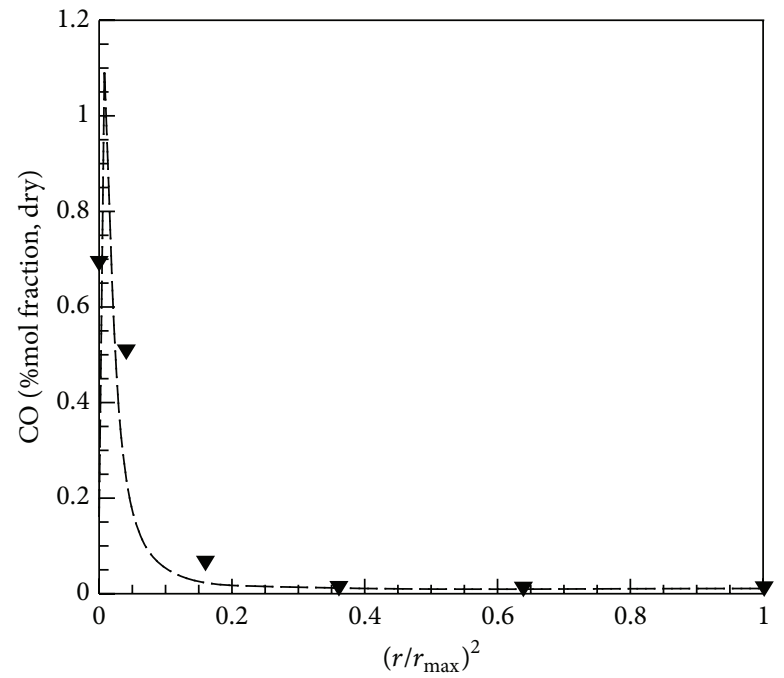

$\nabla$ Experimental

- - Num- 40000 cells

..... Num- 110000 cells

(a)

FIGURE 7: NO (a) and CO (b) concentrations along the radial position between central line and sidewall of the JSR at fixed axial position $(13.46 \mathrm{~mm})$, using the generated five-step mechanism in PSR-PFR obtained from CFD simulations based on two meshes with 40000 and 110000 cells for methane oxidation, comparing with the experimental data for case 3 . 


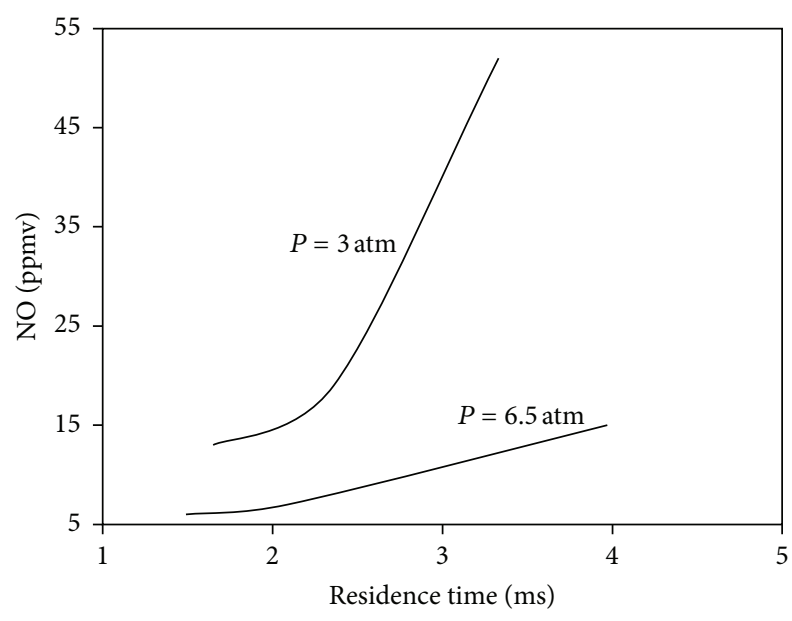

FIGURE 8: NO concentrations versus residence times at different EPLP conditions obtained from the CFD simulations based on the generated five-step global mechanisms using the DE evolutionarybased method.

\section{Competing Interests}

The authors declare that they have no competing interests.

\section{References}

[1] A. Massias, D. Diamantis, E. Mastorakos, and D. A. Goussis, "An algorithm for the construction of global reduced mechanisms with CSP data," Combustion and Flame, vol. 117, no. 4, pp. 685708, 1999.

[2] A. J. Hamer and R. J. Roby, "CFD modeling of a gas turbine combustor using reduced chemical kinetic mechanisms," in Proceedings of the 33rd Joint Propulsion Conference and Exhibit, American Institute of Aeronautics and Astronautics, Seattle, Wash, USA, July 1997.

[3] D. G. Nicol, P. C. Malte, A. J. Hamer, R. J. Roby, and R. C. Steele, "Development of a five-step global methane oxidation-NO formation mechanism for lean-premixed gas turbine combustion," Journal of Engineering for Gas Turbines and Power, vol. 121, no. 2, pp. 272-280, 1999.

[4] I. V. Novosselov and P. C. Malte, "Development and application of an eight-step global mechanism for CFD and CRN simulations of lean-premixed combustors," Journal of Engineering for Gas Turbines and Power, vol. 130, no. 2, Article ID 021502, 2008.

[5] P. Glarborg, J. A. Miller, and R. J. Kee, "Kinetic modeling and sensitivity analysis of nitrogen oxide formation in well-stirred reactors," Combustion and Flame, vol. 65, no. 2, pp. 177-202, 1986.

[6] J. A. Miller and C. T. Bowman, "Mechanism and modeling of nitrogen chemistry in combustion," Progress in Energy and Combustion Science, vol. 15, no. 4, pp. 287-338, 1989.

[7] M. C. Drake and R. J. Blint, "Calculation of NOx formation pathways in propagating laminar high pressure premixed CH4/air flames," Combustion Science and Technology, vol. 75, no. 4-6, pp. 261-285, 1991.

[8] M. G. Michaud, P. R. Westnoreland, and A. S. Feitelberg, "Chemical mechanisms of $\mathrm{NO}_{x}$ formation for gas turbine conditions," Symposium (International) on Combustion: TwentyFourth Symposium on Combustion, vol. 24, no. 1, pp. 879-887, 1992.

[9] D. G. Nicol, R. C. Steele, N. M. Marinov, and P. C. Malte, "The importance of the nitrous oxide pathway to $\mathrm{NO}_{x}$ in leanpremixed combustion," Journal of Engineering for Gas Turbines and Power, vol. 117, no. 1, pp. 100-111, 1995.

[10] K. J. Hughes, T. Turányi, A. R. Clague, and M. J. Pilling, "Development and testing of a comprehensive chemical mechanism for the oxidation of methane," International Journal of Chemical Kinetics, vol. 33, no. 9, pp. 513-538, 2001.

[11] E. L. Petersen, J. M. Hall, S. D. Smith, J. de Vries, A. R. Amadio, and M. W. Crofton, "Ignition of lean methane-based fuel blends at gas turbine pressures," Journal of Engineering for Gas Turbines and Power, vol. 129, no. 4, pp. 937-944, 2007.

[12] L. Pillier, M. Idir, J. Molet, A. Matynia, and S. de Persis, "Experimental study and modelling of NOx formation in high pressure counter-flow premixed $\mathrm{CH}_{4}$ /air flames," Fuel, vol. 150, pp. 394407, 2015

[13] D. A. Goussis and R. E. Kelly, "On the thermocapillary Instabilities in a liquid layer heated from below," International Journal of Heat and Mass Transfer, vol. 33, no. 10, pp. 2237-2245, 1990.

[14] S. H. Lam and D. A. Goussis, "CSP method for simplifying kinetics," International Journal of Chemical Kinetics, vol. 26, no. 4, pp. 461-486, 1994.

[15] H. P. Mallampalli, T. H. Fletcher, and J. Y. Chen, "Evaluation of $\mathrm{CH} 4 / \mathrm{NOx}$ reduced mechanisms used for modeling lean premixed turbulent combustion of natural gas," Journal of Engineering for Gas Turbines and Power, vol. 120, no. 4, pp. 703712, 1998.

[16] C. J. Sung, C. K. Law, and J.-Y. Chen, "Augmented reduced mechanisms for NO emission in methane oxidation," Combustion and Flame, vol. 125, no. 1-2, pp. 906-919, 2001.

[17] A. Belcadi, M. Assou, E. Affad, and E. Chatri, " $\mathrm{CH}_{4} / \mathrm{NO}_{x}$ reduced mechanisms used for modeling premixed combustion," Energy and Power Engineering, vol. 4, no. 4, pp. 264-273, 2012.

[18] M. F. Karalus, K. B. Fackler, I. V. Novosselov, J. C. Kramlich, and P. C. Malte, "A skeletal mechanism for the reactive flow simulation of methane combustion," in Proceedings of the ASME Turbo Expo 2013: Turbine Technical Conference and Exposition (GT '13), San Antonio, Tex, USA, June 2013.

[19] I. V. Novosselov, Eight step global kinetic mechanism on methane oxidation with nitric oxide formation for lean premixed combustion turbine [M.S. thesis], University of Washington, Seattle, Wash, USA, 2001.

[20] M. M. Thornton, P. C. Malte, and A. L. Crittenden, "A wellstirred reactor for the study of pyrolysis and oxidation kinetics: carbon monoxide and n-pentane oxidation," Combustion Science and Technology, vol. 54, no. 1-6, pp. 275-297, 1987.

[21] R. A. Corr, P. C. Malte, and N. M. Marinov, "Evaluation of $\mathrm{NO}_{x}$ mechanisms for lean, premixed combustion," Journal of Engineering for Gas Turbines and Power, vol. 114, no. 2, pp. 425-434, 1992.

[22] R. C. Steele, P. C. Malte, D. G. Nicol, and J. C. Kramlich, " $\mathrm{NO}_{x}$ and $\mathrm{N}_{2} \mathrm{O}$ in lean premixed jet stirred flames," Combustion and Flame, vol. 100, pp. 440-449, 1995.

[23] R. C. Steele, A. C. Jarrett, P. C. Malte, J. H. Tonouchi, and D. G. Nicol, "Variables affecting $\mathrm{NO}_{\mathrm{x}}$ formation in lean-premixed combustion," Journal of Engineering for Gas Turbines and Power, vol. 119, no. 1, pp. 102-107, 1997. 
[24] K. U. M. Bengtsson, P. Benz, R. Schären, and C. E. Frouzakis, " $\mathrm{N}_{y} \mathrm{O}_{x}$ formation in lean premixed combustion of methane in a high-pressure jet-stirred reactor," Symposium (International) on Combustion, vol. 27, no. 1, pp. 1393-1399, 1998.

[25] T. R. Shuman, NOx and CO formation for lean premixed methane-air combustion in a jet stirred reactor operated at elevated pressure [Ph.D. thesis], University of Washington, Washington, DC, USA, 2000.

[26] S. R. Turns, An Introduction to Combustion, McGraw-Hill, New York, NY, USA, 3rd edition, 2012.

[27] R. J. Kee, F. M. Rupley, J. A. Miller et al., CHEMKIN Release 4.0, Reaction Design, San Diego, Calif, USA, 2004.

[28] K. V. Price, R. M. Storn, and J. A. Lampine, Differential Evolution-A Practical Approach to Global Optimization, Natural Computing Series, 2005.

[29] R. C. Steele, J. H. Tonouchi, D. G. Nicol, D. C. Horning, P. C. Malte, and D. T. Pratt, "Characterization of $\mathrm{NO}_{x}, \mathrm{~N}_{2} \mathrm{O}$, and $\mathrm{CO}$ for lean-premixed combustion in a high-pressure jet-stirred reactor," Journal of Engineering for Gas Turbines and Power, vol. 120, no. 2, pp. 303-310, 1998.

[30] T. Rutar and P. C. Malte, "No ${ }_{x}$ formation in high-pressure jetstirred reactors with significance to lean-premixed combustion turbines," Journal of Engineering for Gas Turbines and Power, vol. 124, no. 4, pp. 776-783, 2002.

[31] G. K. Batchelor, An Introduction to Fluid Dynamics, Cambridge University Press, Cambridge, UK, 1967.

[32] F. S. Lien and M. A. Leschziner, "Assessment of turbulencetransport models including non-linear rng eddy-viscosity formulation and second-moment closure for flow over a backward-facing step," Computers and Fluids, vol. 23, no. 8, pp. 9831004, 1994. 


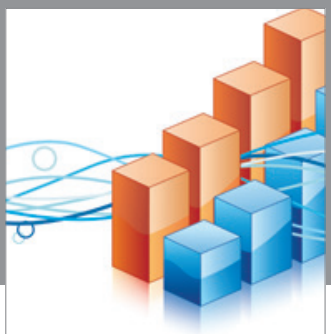

Advances in

Operations Research

vatem alat4

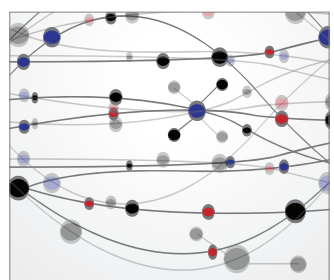

\section{The Scientific} World Journal
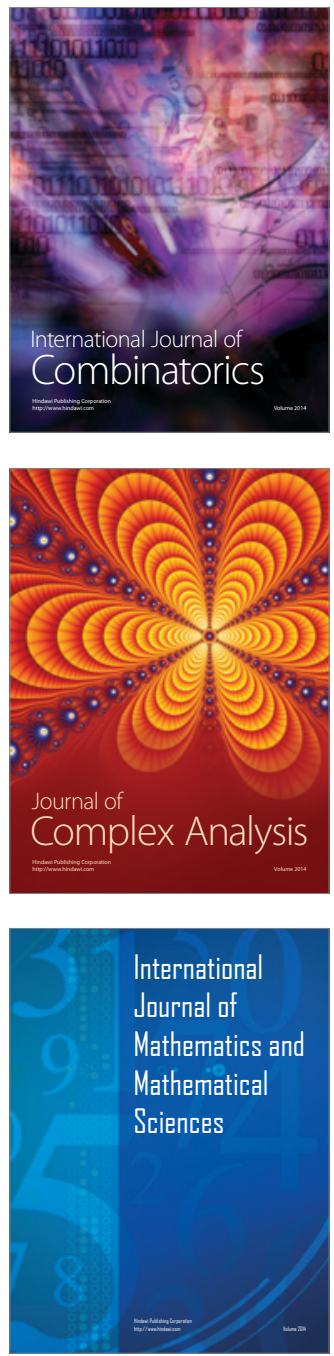
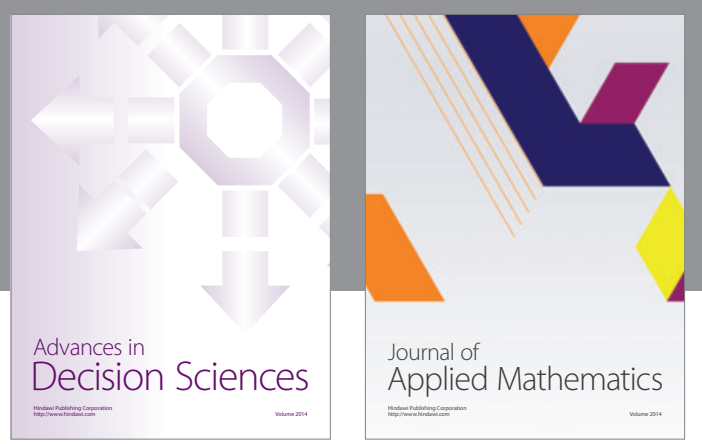

Algebra

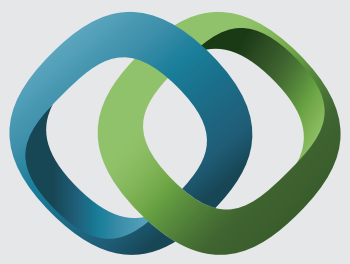

\section{Hindawi}

Submit your manuscripts at

http://www.hindawi.com
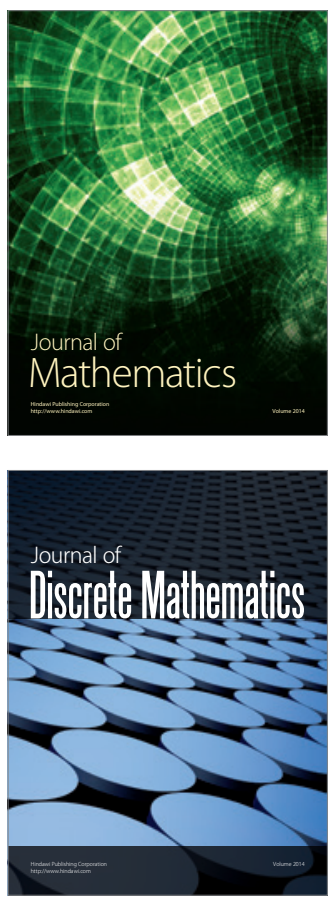

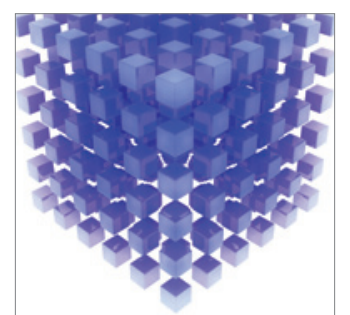

Mathematical Problems in Engineering
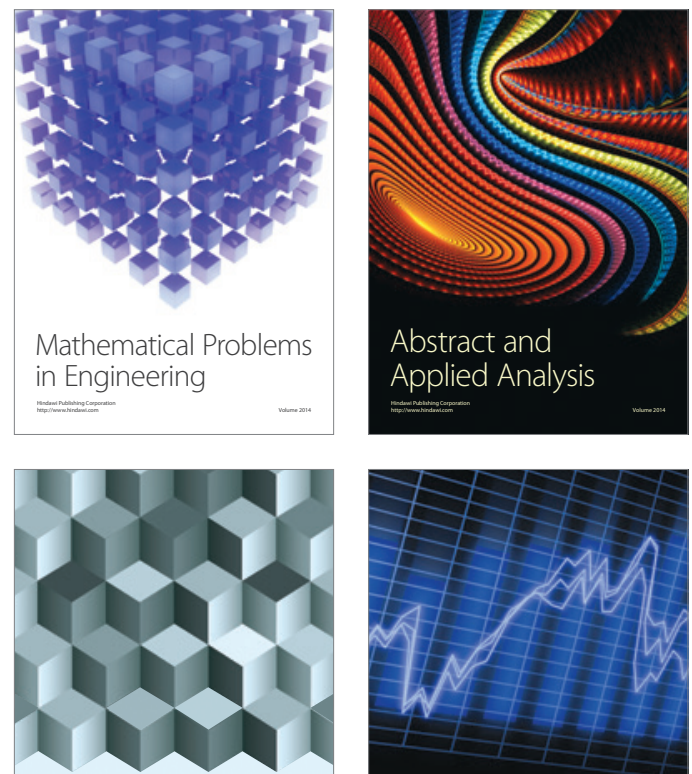

Journal of

Function Spaces

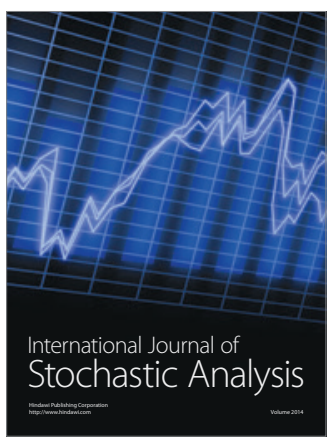

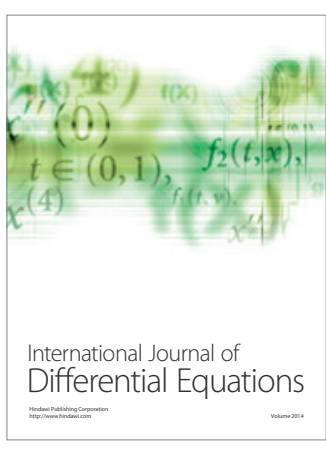
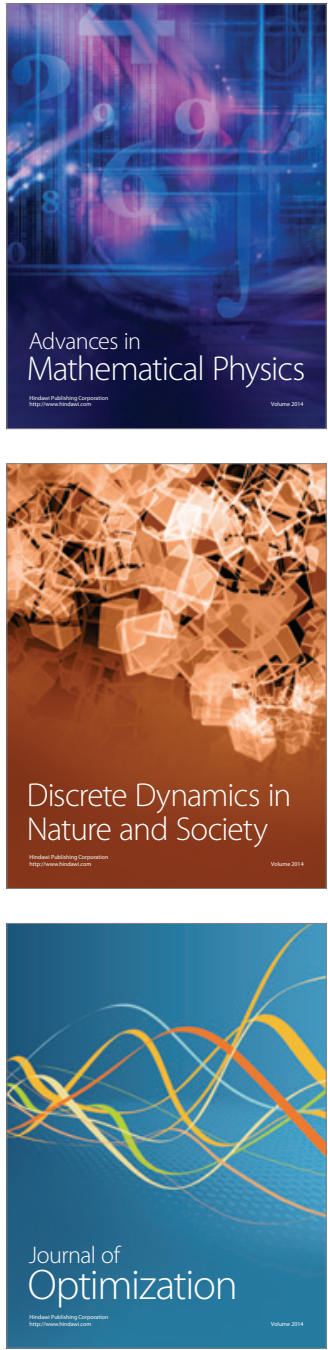